\title{
A Short Review on Various Purification Techniques Suitable for Biohydrogen-Mixed Gases
}

\author{
Nor Azira Abdul Muin ${ }^{1}$, Abdullahi Nwaha Isah ${ }^{2}$, Umi Aisah Asli ${ }^{1,3^{*}}$, Aziatul Niza Sadikin ${ }^{1}$, Norafneeza \\ Norazahar ${ }^{1,4}$, Mohd Johari Kamaruddin ${ }^{1,4}$, Mimi Haryani Hassim ${ }^{1,4}$, Ho Wai Shin ${ }^{1,5}$, Nur Raudhah Azman \\ ${ }^{1}$ School of Chemical \& Energy Engineering, Faculty of Engineering, Universiti Teknologi Malaysia, 81310 \\ Johor Bahru Johor, Malaysia \\ ${ }^{2}$ Department of Chemical Engineering Technology, School of Engineering Technology, The Federal \\ Polytechnic Nasarawa, Nasarawa State, Nigeria \\ ${ }^{3}$ Innovation Centre of Agritechnology for Advanced Bioprocessing, Universiti Teknologi Malaysia Pagoh, \\ Pagoh Edu Hub, 84600 Pagoh, Johor, Malaysia \\ ${ }^{4}$ Centre of Hydrogen Energy, Universiti Teknologi Malaysia, 81310 Johor Bahru Johor, Malaysia \\ ${ }^{5}$ PROSPECT, Universiti Teknologi Malaysia, 81310 Johor Bahru Johor, Malaysia
}

*Corresponding author: umiaisah@cheme.utm.my

\section{Article History}

\begin{abstract}
The need of establishment of biohydrogen purification techniques is due the fact that biohydrogen production will be completely transformed into industrial scale soon or later. For biohydrogen process development to be commercially feasible, all the process involved, including purification should be low cost, practical and efficient; particularly when the biohydrogen production is technically challenging. In any case, carbon dioxide and other gaseous impurities are usually evolved during hydrogen production, and highly purified hydrogen is desirable in fuel cells application and other hydrogenation processes. Particularly, is critical to achieve high purity of hydrogen especially in a fuel cell application where it requires $99.9 \%$ only hydrogen. This paper reviews four main principle methods that are suitable for biohydrogen mixed gases, namely cryogenic separation, absorption, adsorption and membrane separation. The comparison based on their strengths and weaknesses, regarding the rate and yield of hydrogen, energy requirement and efficiency in terms of hydrogen selectivity, recovery and purity for fuel cell application. Cryogenic separation is among the earliest technique used for hydrogen purification. Though, due to the low temperature requirement, cryogenic separation is least preferred as gas separation is energy intensive and costly. Cyrogenic separation is commonly combine with membrane separation. It was also acknowledged that the membrane separation technique is widely used for biohydrogen purification. Most of research mostly in advancement of the membrane for high selectivity for hydrogen and low selectivity for carbon dioxide.Another method, pressure swing adsorption (PSA) is one of commonly used in conventional hydrogen purification. The hydrogen purity produced by PSA was higher than absorption but the cost to operate it is the same at the expense of low hydrogen recovery. Also, chemical absorption of hydrogen separation from mixed gaseous mixture is discussed due to its simplicity of operation and possible to operate using existing common absorber.
\end{abstract}

Keywords: Biohydrogen production, hydrogen purification, pressure swing adsorption (PSA), absorbation, membrane, sustainable, energy, fuel cell.

\subsection{HYDROGEN AS AN ALTERNATIVE FUEL}

Hydrogen is a universal clean and efficient secondary energy carrier with high energy value by weight (142MJ/kg), which can be used for energy storage and transportation and converted into electricity via fuel cells with high efficiency without carbon prints [1][2]. Hydrogen has been identified as an alternative energy carrier to the conventional fossil fuels because it is clean, renewable and does no contribute to environmental problems like global warming resulting from profuse 
release of greenhouse gases.

Hydrogen can also be produced from biomass by using thermochemical or biological processes. Thermochemical processes are much faster and offer higher stoichiometric yield of hydrogen. However, it requires high energy thus high operating cost. Whereas, biological processes are more environmental friendly and less energy intensive, as they operate under mild conditions [3]. Biological methods can be subdivided into three; biophotolysis, photofermentation and dark fermentation. Between the three methods, dark fermentation produces the highest biohydrogen yield [1]. Hydrogen which is produced by microbes through biological activities such as biophotolysis and fermentation can be classified as biohydrogen. The various available processes to produce hydrogen is depicted in Figure 1.

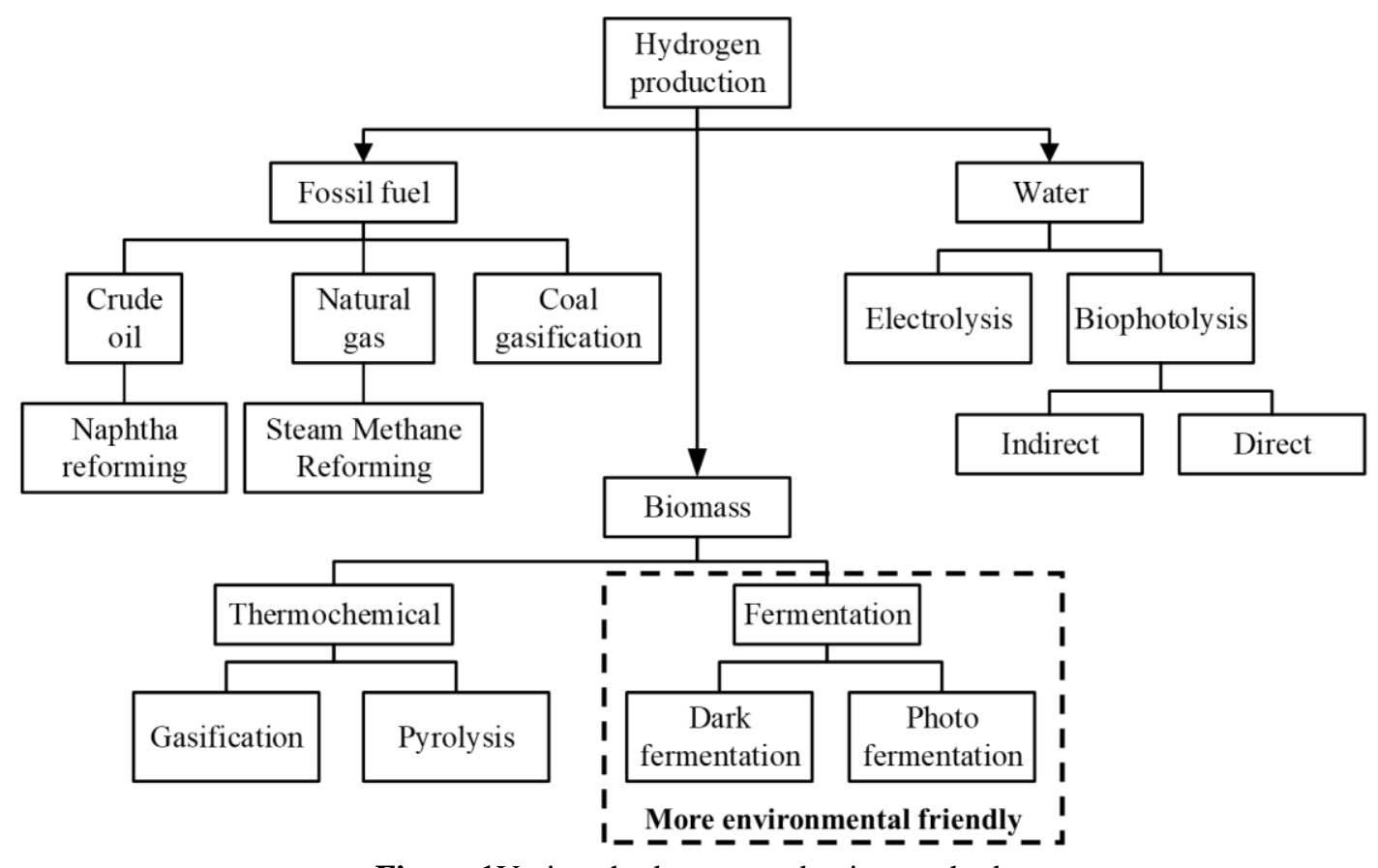

Figure 1Various hydrogen production methods

\subsection{Gas Composition of Raw Biohydrogen versus Raw Conventional Hydrogen}

Conventional hydrogen is typically produced from fossil fuels such as natural gas, crude oil and coal. As mentioned by Debabrata et al. [1], 96\% of world hydrogen production was from fossil fuel, whereas $3.9 \%$ from water electrolysis and $0.1 \%$ from other production methods. Regarding biological methods of hydrogen production, they are still at advancing stage, since reseaches are geared towards maximizing the yield of biohydrogen via improved microorganism, design of bioreactor and advancement of bioprocess [4]. The differences between conventional hydrogen and biohydrogen are in terms of reactants for their production, method of production, gas composition, and gas condition. The raw materials to produce conventional hydrogen and biohydrogen are from different sources. Hence, the gas composition is expected to be different as well. To understand how this will affect the product yield, each process is briefly explained later.

The widely reported methods of biohydrogen production are classified into biophotolysis and fermentation. Biophotolysis is further categorized into direct biophotolysis and indirect biophotolysis, while fermentation is subdivided into dark fermentation and photofermentation. Photofermentation and biopholysis are examples of light-dependent processes, while dark anaerobic fermentation is an example of light-independent process [3] and [4].

Biophotolysis is a process of biohydrogen production where photoautotrophic organism such as microalgae and cyanobacteria are used with the aid of sunlight to convert water into hydrogen and oxygen molecules. In direct biophotolysis, sunlight is used as source of energy and carbon(IV) oxide as carbon source to break water molecule into hydrogen $\left(\mathrm{H}_{2}\right)$ and oxygen $\left(\mathrm{O}_{2}\right)$ under the anaerobic condition, as presented in Equation 1 [1][3][4]. The process is quite similar to photosynthesis where water is splits into protons $\left(\mathrm{H}^{+}\right)$and electrons $\left(\mathrm{e}^{-}\right)$within phytosynthesis system.

$$
2 \mathrm{H}_{2} \mathrm{O}+\text { light energy } \rightarrow 2 \mathrm{H}_{2}+\mathrm{O}_{2}
$$


Rahman et al. [3] reported that the hydrogen yield from direct biophotolysis was between $0.05-30 \mathrm{ml} \mathrm{H}_{2} \mathrm{~L}^{-1} \mathrm{~h}^{-1}$. Direct biophotolysis is advantageous in a way that it does not require any organic carbon substrate for the growth of microorganism [6]. Indirect biophotolyis involves separation of the hydrogen and oxygen evolution reactions into separate stages [2] where light is used as energy source for the conversion of organic acids into $\mathrm{CO}_{2}$ and $\mathrm{H}_{2}$. as shown in Equation 2 to 4.

$$
\begin{aligned}
& 6 \mathrm{H}_{2} \mathrm{O}+6 \mathrm{CO}_{2}+\text { light energy } \rightarrow \mathrm{C}_{6} \mathrm{H}_{12} \mathrm{O}_{6}+6 \mathrm{O}_{2} \\
& \mathrm{C}_{6} \mathrm{H}_{12} \mathrm{O}_{6}+6 \mathrm{H}_{2} \mathrm{O} \rightarrow 12 \mathrm{H}_{2}+6 \mathrm{CO}_{2} \\
& \text { Overall reaction: } 12 \mathrm{H}_{2} \mathrm{O}+\text { light energy } \rightarrow 12 \mathrm{H}_{2}+6 \mathrm{O}_{2}
\end{aligned}
$$

In photofermentation, carbon dioxide is produced during the process instead of oxygen [7] which the simplified chemical reaction of photofermentation is as shown in Equation 5.

$$
\mathrm{CH}_{3} \mathrm{COOH}+2 \mathrm{H}_{2} \mathrm{O} \rightarrow 2 \mathrm{CO}_{2}+4 \mathrm{H}_{2}
$$

Another biological process for biohydrogen is dark fermentation is a where hydrogen is produced by anaerobic bacteria grown in the dark on carbohydrate-rich substrates, and it is considered the simplest process of obtaining biohydrogen, as presented in Equations 6 and 7 [8][1][9-10]. This mixture is not suitable for direct use in fuel cell because the hydrogen concentration is not sufficiently high $(<99 \%)$ and the carbon dioxide present negatively affects their operation [11]. A maximum of $4 \mathrm{~mol} / \mathrm{mol}$ glucose is obtained when acetate is the end product, and half of this yield/mol glucose is obtained when butyrate is the end product.

$$
\begin{aligned}
& \mathrm{C}_{6} \mathrm{H}_{12} \mathrm{O}_{6}+2 \mathrm{H}_{2} \mathrm{O} \rightarrow 2 \mathrm{CH}_{3} \mathrm{COOH}+2 \mathrm{CO}_{2}+4 \mathrm{H}_{2} \\
& \mathrm{C}_{6} \mathrm{H}_{12} \mathrm{O}_{6}+2 \mathrm{H}_{2} \mathrm{O} \rightarrow \mathrm{CH}_{3} \mathrm{CH}_{2} \mathrm{COOH}+3 \mathrm{CO}_{2}+4 \mathrm{H}_{2}
\end{aligned}
$$

In terms of classification by temperature, dark fermentation is categorized into four temperature range: hyperthermophiles, 79 to $115{ }^{\circ} \mathrm{C}$; thermophiles, 40 to $110{ }^{\circ} \mathrm{C}$; mesophiles, 10 to $50{ }^{\circ} \mathrm{C}$, and psychrophiles, 0 to $30{ }^{\circ} \mathrm{C}$. Schröder et al. [12] reported that dark fermentative conversion of glucose at temperature of $80{ }^{\circ} \mathrm{C}$ resulted to $\mathrm{H}_{2}$ formation close to $4 \mathrm{~mol} / \mathrm{mol}$ glucose.

According Kraemer and Bagley [13], the $\mathrm{H}_{2}$ yield must be at least $10 \mathrm{~mol} \mathrm{H}_{2} / \mathrm{mol}$ glucose for the production to be

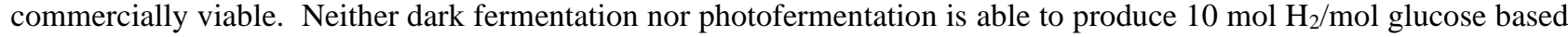
on their stoichiometric Equations 8 and 9, respectively. However, when dark and photo fermentation is integrated, it is possible to produce theoretical maximum yield of $12 \mathrm{~mol} \mathrm{H}_{2} / \mathrm{mol}$ glucose, as presented in Equation 10 [14].

$$
\begin{aligned}
& \mathrm{C}_{6} \mathrm{H}_{12} \mathrm{O}_{6}+2 \mathrm{H}_{2} \mathrm{O} \rightarrow 2 \mathrm{CH}_{3} \mathrm{COOH}+2 \mathrm{CO}_{2}+4 \mathrm{H}_{2} \\
& 2 \mathrm{CH}_{3} \mathrm{COOH}+4 \mathrm{H}_{2} \mathrm{O} \rightarrow 4 \mathrm{CO}_{2}+8 \mathrm{H}_{2} \\
& \text { Over all reaction: } \mathrm{C}_{6} \mathrm{H}_{12} \mathrm{O}_{6}+6 \mathrm{H}_{2} \mathrm{O} \rightarrow 6 \mathrm{CO}_{2}+12 \mathrm{H}_{2}
\end{aligned}
$$

In general, biological hydrogen production is majorly associated with lower rate and yield as compared to the conventional hydrogen production methods via thermochemical processes. This is in connection with partial pressure of hydrogen gas in the produced mixed gas mixture, competing reactions, bioprocess technology, insufficient active hydrogenase enzyme, inefficient hydrogen-producing cultures, and method of purification of hydrogen. The metabolic shift from acetic acid generation to solvent of hydrogen-consuming organic acid generation, and consumption of hydrogen by uptake of hydrogenase and homoacetogens, reduces biohydrogen production [5] and [15]. These bottlenecks could be eventually overcome because extensive research and development was focusing on various solution such as development of genetically modified microorganisms to ease the biosynthesis, improvement of the bioreactor design, molecular engineering of the key enzyme hydrogenase, as well as the improvement of two stages dark and photofermentation processes [16]. As for the composition of raw biohydrogen, not many reports were detailing out its composition. Most reports mentioned biohydrogen mainly contain $\mathrm{H}_{2}$ and $\mathrm{CO}_{2}[17-18,11]$. It is possible due to the presence of $\mathrm{CH}_{4}$ can be eliminated by avoiding using methanogenesis bacteria for the fermentation. Moreover, it is very unlikely to use 
methanogenesis bacteria when the intent is to produce hydrogen since methanogenesis bacteria is selected when the objective is to produce $\mathrm{CH}_{4}$. As for the $\mathrm{H}_{2} \mathrm{~S}$, it presence can be eliminated by selecting sulfur consuming bacteria. Most of photofermentative bacteria consume sulfur except for purple non-sulfur bacteria.

\subsection{HYDROGEN PURIFICATION TECHNOLOGIES SUITABLE FOR BIOHYDROGEN MIXED GAS}

In this review, biohydrogen purification is refers to a system which allows hydrogen (particularly from biological processes) to be isolated from the mixed gas stream (composed of hydrogen, $\mathrm{CO}_{2}$, and other gases) and used as a clean fuel or feedstock. The process selected based on the previous proven studies including other establish method of hydrogen purification that applicable to biohydrogen mixed gasses subsequently from the production process. The distinguish properties of biohydrogen from typical hydrogen gas was taken into consideration on purification methods where biohydrogen that commonly came from wet medium has significant moisture content. Since the biological process has not well established yet, it is quite difficult to determine the real composition of biohydrogen in the gas production. The highest biohydrogen composition produced from biological process found in the literature review was reported by Morsy [18] where the biohydrogen composition obtained from the fermentation process at $35^{\circ} \mathrm{C}$ and 1 atm was $56 \%$ of $\mathrm{H}_{2}$ with the rest $44 \%$ was $\mathrm{CO}_{2}$. Hence, generally if the biological process is successful, the composition of gas mixture will be mainly $\mathrm{H}_{2}$ and $\mathrm{CO}_{2}$. In the recent past, methods for separating hydrogen from other gases (such as $\mathrm{CO}_{2}$ ) are mainly pressure swing adsorption (PSA), cryogenic distillation and adsorption with either amines or aqueous solutions of calcium carbonate and ionic liquids as absorbents with high selective capacity for $\mathrm{CO}_{2}$ separation from other gases [19].

\subsection{Cryogenic Separation}

In the earliest day, cryogenic separation was used to separate hydrogen from air. Cryogenic is a technology which utilizes low temperature condition below $120 \mathrm{~K}\left(-153{ }^{\circ} \mathrm{C}\right)$ to produce so called "cryogenic temperature" that have effects on the materials properties and system behavior [20]. In cryogenic separation system, it involves compression, refrigeration and separation with the influence of phase transition characteristics of gas mixtures, in order to have relatively low energy penalty and high purity [21]. For a multi components gas stream involving biohydrogen, it is possible to use cryogenic separation as hydrogen has the lowest boiling point among all components in the gas stream. In addition, it is attractive because it is a clean and safe technology, which does not involve chemical additives [22]. However, it is energy intensive, because of the amount of energy required to provide the refrigeration necessary for the process, particularly for more dilute $\mathrm{CO}_{2}$ streams. And it requires large equipment size. The main issue with this technique is $\mathrm{CO}_{2}$ sublimate (phase change of gas to solid) at pressure of $1 \mathrm{~atm}$. To overcome this problem, the operating pressure is increased to a point where the phase change is gas to liquid. Another problem with cryogenic separation is that hydrogen sulfide $\left(\mathrm{H}_{2} \mathrm{~S}\right)$ must be removed before feeding the gas into cryogenic system. This is mainly because $\mathrm{H}_{2} \mathrm{~S}$ will solidify at the cryogenic condition and will lead to clogging of the system [23] and damage to rotating equipment. For industrial scale of hydrogen production, it is being replaced with a pressure swing adsorption (PSA) system [24], which has lower operating cost, simpler to operate, easier to maintain and produce higher hydrogen purity [25] than cryogenic separation.

\subsection{Pressure Swing Adsorption (PSA)}

In a PSA, hydrogen stream purity is increase by adsorbing the impurities using solid adsorbents through adsorption mechanism, which physically binds impurities molecules onto the adsorbents surface [26]. PSA is commonly applied to purify hydrogen to a required level depending on the difference of binding forces of gas molecules with the adsorbent. During the PSA process, the hydrogen is revered and purified at a pressure close to the feed pressure, while adsorbed impurities are removed by lowering the pressure[27]. There are four steps involve in operating a PSA system. They are adsorption, depressurization, blowdown and pressurization. Brief explanations on the steps are as follows:

a. Adsorption : Crude hydrogen gas is fed from bottom of the vessel and impurities will be adsorbed onto adsorbent as it pass through the multilayer packed bed producing high purity hydrogen gas.

b. Depressurization: Once switching is completed, the adsorbent vessel will be depressurized down to a pressure slightly above atmospheric pressure [26].

c. Purging: Once depressurization is completed, the adsorbent is purge using depressurized gas from depressurization vessel, and onward purge with pure $\mathrm{H}_{2}$ to desorb any remaining impurities that might still bind with the adsorbent.

d. Pressurization: Lastly, the adsorbent is re-pressurize with product gas prior reintroduction of the raw gas. 
According to Moon et al. [28], the PSA recovery is between 73.3 to 77.64\%. The multistep in PSA is controlled using a multiple control valves, a complex network of instrumentations and control systems. However, PSA for hydrogen purification has a drawback of low hydrogen recovery [29]. It is on this premise that membrane gas separation is desirable.

\subsection{Chemical Absorption}

There are two main sections in an absorption process; the absorber and the stripper. At the absorber section, the raw gas is fed at the bottom and leaves the absorber at the top, whereas lean solvent is fed at the top side of the absorber and rich solvent exits through the bottom of the absorber. Such flow arrangement is necessary to create counter-current which would optimize the absorption [30]. Upon exiting the absorber, the rich solvent is sent to the stripper section to be regenerated by flashing out the impurities. The stripper is normally set at higher temperature and/or lower pressure than the absorber which is preferred operating conditions, as it will optimize the impurities removal from the solvent.

The temperature of the biohydrogen is expected to be within the mesophiles region, which is between 20 to $45^{\circ} \mathrm{C}$, while the pressure is expected to be slightly above atmospheric pressure. In view of this temperature and pressure of the feed gas, separation by chemical absorption can be one of option. This is mainly because, with chemical absorption, it is possible to be operated at low pressure while producing high purity product stream. Factors affecting absorption include $\mathrm{pH}$ of the solvent and the concentrations and temperatures of both the gas and the solvent. A solvent is considered economically attractive if it is has low energy requirements, can be regenerated easily, does not impose environmental impacts and cost effective [31].

One of previous work [32], the chemical absorption by using piperazine (PZ) as an activator in methyldiethanolamine (MDEA) solution in the first stage and caustic or $\mathrm{NaOH}$ solution in the second stage was used to prove a success in producing $99.9 \%$ purity of hydrogen gas from the initial gas mixture containing $50 \mathrm{~mol} \% \mathrm{H}_{2}$ and $50 \mathrm{~mol}^{2} \mathrm{CO}_{2}$. This method is feasible to be adopted in biohydrogen production as, with chemical absorption, it is possible to be operated at low pressure while producing high purity product stream. The possible reaction path for $\mathrm{PZ}$ regeneration and $\mathrm{CO}_{2}$ transport into MDEA is as proposed in Figure 2. As shown in Figure 2, at the interface $\mathrm{CO}_{2}$ molecules react with $\mathrm{PZ}$ to form PZ carbamate and protonated PZ. Then, as the PZ is nearly consumed by $\mathrm{CO}_{2}$, the carbamate will now release the $\mathrm{CO}_{2}$ to MDEA phase [33] regenerating back the PZ. Within the MDEA phase, $\mathrm{CO}_{2}$ molecules will undergo base catalyst hydration with the water and MDEA molecules to form bicarbonate and protonated MDEA. The negative charged PZ will react with protonated $\mathrm{PZ}$ hence regenerating $\mathrm{PZ}$ molecules.

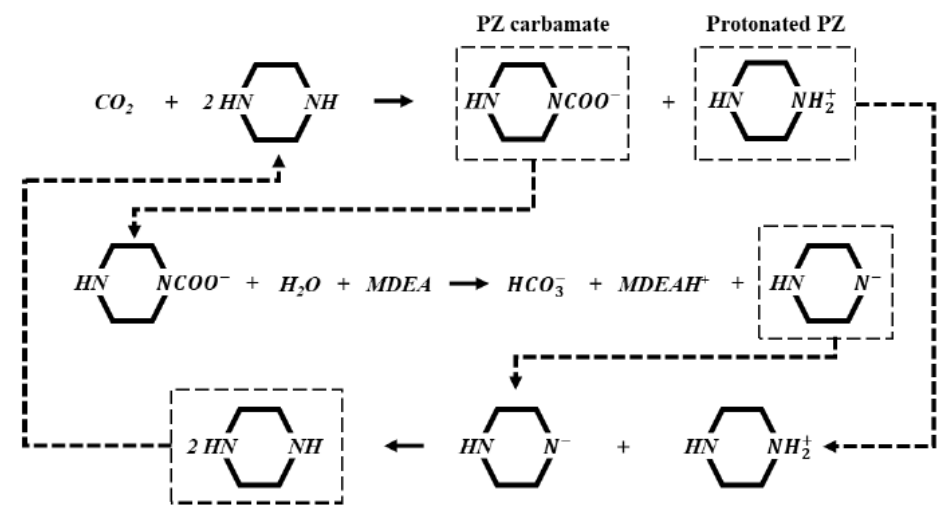

Figure 2 Proposed reaction path for $\mathrm{PZ}$ regeneration and $\mathrm{CO}_{2}$ transport into $\mathrm{MDEA}$ phase

Though, that reaction needs a polishing stage by using caustic $(\mathrm{NaOH})$ as shown in Equation 11 . The reaction is not reversible where $\mathrm{NaOH}$ will be consumed in the process.

$$
\mathrm{CO}_{2}+2 \mathrm{NaOH} \rightarrow \mathrm{Na}_{2} \mathrm{CO}_{3}+\mathrm{H}_{2} \mathrm{O}
$$

Though, the drawbacks of those complex chemical absorptions are high energy requirement and severe corrosion problems [34].

\subsection{Membrane Separation}

Among biohydrogen purification technology, membrane separation is the vastly reported in the literature and the most recent technology of interest [35]. Membrane separation separates impurities based on relative permeability of the impurities and the desired gas. The typical parameters of differentiating among the hydrogen separation membrane are composition, diffusion mechanism, driving force, operation temperature, relative permeability, typical selectivity and 
relative cost [36].

From technical view, permeability and selectivity are the two most important criteria for evaluating the performance of a membrane. Microporous membranes posses' relatively high permeability with considerable selectivity and promising thermal and chemical stability. High permeability of hydrogen with low permeability of $\mathrm{CO}_{2}$ is desired in order to consider the membrane as selective for the specific mixed gas separation [34].The permeability and selectivity depend on operation conditions such as temperature, pressure, humidity and gas compositions, among others. Permeability acts as a selective barrier, which only allow certain component to pass through easily than others [36].There are many factors affecting the rate of permeability such as gas compositions, membrane material of construction, partial pressure of permeate across membrane and the operating condition such as temperature and pressure [37]. Besides permeability, another important criterias in assessing membrane performance is the selectivity. By definition, selectivity is the ability of the membrane to separate two components in input mixed gas stream. It is used to measure the differences in permeability of two components [35]. It was found that higher selectivity produced higher purity product [25] but reduction in permeability resulted to lower gas yield.

There are many types of membrane used in hydrogen separation and purification. It can be categorized in accordance to the material used for its fabrication such as polymeric membrane, dense metal membrane or microporous membrane [38, 3]. Furthermore, inorganic membrane is more suitable for high temperature operation such as hydrogen production by water gas shift (WGS) [25]. Polymeric membranes dominate the hydrogen separation membrane market in preference to metal and inorganic membranes because of their lower material and manufacturing cost, easy accessibility and mild operation conditions [39]. The most common hydrogen separation membranes are made from commonly available polymers such as cellulose acetate, polysulfone, polyethersulfone, polyimide, polybenzimidazole, polyetherimide etc. In recent times, polyimide and polybenzimidazole-based membranes are very attractive for hydrogen separation because of their improve performance, promising structure and thermal stabilities under hasrh operation conditions. Compared with conventional technologies, the use of emerging polymer membranes in separation processes can lower energy consumption, reduce maintenance requirements, and increase selectivity. The hydrogen selectivity of a membrane can be increased if the membrane surface has dense and pose free microstructure.

Bakonyi et al. [40] reported that the feasibility of a membrane based gas purifictation system is dependent on three main factors: 1) material selection for membrane fabrication, 2) design and configuration of membrane modules, 3) operation conditions. The factors the govern the separation process for a given membrane module made of a certain material are: 1) gas composition, 2) pressure, 3) temperature.

Gas composition: The composition of the gas to be separated is a key factor that can affecting separation efficiency to be achieved. This is because the interactions take place between the gas molecules themselves and /or the gas molecules and the polymer will alter the permeation behavior of the individual gas species [41]. The separation of hydrogen from complex biological gas mixtures is a challenging task because several compounds, such as $\mathrm{CO}_{2}$, hydrogen sulphide, water vapour, etc. pose a threat to achieve the required enhancement efficiency [42][11].

Pressure: Partial inlet/ outlet pressure of hydrogen, as well as temperature, are the best parameters for membrane process. Gases such as oxygen, nitrogen and hydrogen can permeate through the polymer without modifying the polymer's properties due to their relatively low solubility in the polymer. Therefore, with the pressure's increase, the gas permeability slightly decreases. Conversely, highly sorbing gases like carbon dioxide can induce a swelling of the polymer matrix (plasticization effects), leading to a large increase of the gas permeability with increase in pressure [4344][34].

Temperature: Dense polymer membranes are suitable to isolate hydrogen from gas mixtures at moderately lower temperature around $110^{\circ} \mathrm{C}[40]$. Depending on the polymer, the membrane performance can be improved by an increase of temperature. The permeability coefficient of nitrogen, methane and hydrogen increases with increasing temperature, while for carbon dioxide, it decreases with increasing temperature. Permeate flux is very sensitive to the feed temperature. Permeate flux increases as the feed temperature increases, due to the decrease of feed viscosity with an increase in the feed temperature [43-44].

In general, the advantages of membrane gas separation over other traditional gas upgrading processes (like pressure swing adsorption (PSA), and cryogenic distillation) are higher energy efficiency, simplicity in operation and control, low cost of installation and maintenance, compactness and portability[11][45].

\subsection{Comparison of All Methods}

Each method has both advantages and disadvantages for the purification of biohydrogen, especially when the variability of crude fermentation gas is taken into account. The method to be chosen for biohydrogen purification from fermentation process is depending on the variation of gas produced from the main fermentation process. Advantages and disadvantages of the processes are summarized in Table 2 . 
Table 2: Summary of advantages and disadvantages for all types of hydrogen purification technologies

\begin{tabular}{|c|c|c|}
\hline Technology & Advantages & Disadvantages \\
\hline Cryogenic separation & $\begin{array}{l}\text { - Suitable for high } \mathrm{CO}_{2} \text { concentration in } \\
\text { feed gas }(\sim 90 \mathrm{~mol} \%) \\
\text { - Enable production of liquid } \mathrm{CO}_{2}\end{array}$ & $\begin{array}{l}\text { - Process is energy intensive } \\
\text { - Water need to be removed prior } \\
\text { feeding into the process or it will cause } \\
\text { clogging and equipment damage. }\end{array}$ \\
\hline Chemical Absorption & $\begin{array}{l}\text { - } \text { High } \mathrm{CO}_{2} \text { recovery }(98 \%) \\
\text { - Suitable for low pressure gas stream } \\
\text { - Suitable for biomass feed gas } \\
\text { - Less energy requirement for } \mathrm{H}_{2} \text { gas } \\
\text { compression as } \mathrm{CO}_{2} \text { is removed upfront }\end{array}$ & $\begin{array}{l}\text { - High energy requirement for solvent } \\
\text { regeneration } \\
\text { - Loss of solvent }\end{array}$ \\
\hline Adsorption & $\begin{array}{l}\text { - Produced high purity } \mathrm{H}_{2} 99.5 \text { - } \\
99.9999 \%\end{array}$ & $\begin{array}{l}\text { - High energy, complex and high } \\
\text { pressure system. } \\
\text { - Low product recovery }(75-90 \%) \\
\text { - Economical for high } \mathrm{H}_{2} \text { concentration } \\
\text { feed gas }(\sim 80 \mathrm{~mol} \%)\end{array}$ \\
\hline Membrane separation & $\begin{array}{l}\text { - No moving parts and simple operation } \\
\text { - Minimal utility requirement }\end{array}$ & $\begin{array}{l}\text { - Low product purity and low product } \\
\text { recovery }(<90 \%) \\
\text { - } \text { Required pre-filter and coalescer } \\
\text { - } \text { Clogging due to bacterial growth } \\
\text { - Gas compression is required to } \\
\text { maintain differential pressure across } \\
\text { membrane }\end{array}$ \\
\hline
\end{tabular}

\subsection{CONCLUSION}

In this review, four different methods of hydrogen production have been highlighted and evaluated in terms of their weakness and strength in purifying biohydrogen from a mixed gas mainly contains $\mathrm{CO}_{2}$. Among the hydrogen separation techniques researched on, membrane separation is preferable, especially if the membrane is made of advanced materials with high selectivity for hydrogen and low selectivity for carbon dioxide. The other three methods, cryogenics, pressure swing adsorption and chemical absorption were also feasible due to the maturity of the technology, and possible to utilize the available facilities in the gas separation industries. It is also possible to utilize integration of any methods in purifying biohydrogen from mixed gas, so that each strength and weaknesses could complement one to another.

\section{Acknowledgements}

The authors would like to acknowledge the research grants from Universiti Teknologi Malaysia with the grant no. Q.K130000.3509.06G37.

\section{References}

[1] Debabrata, D., Namita, K., \& Chitralekha Dasgupta;, N. (2014). Biohydrogen Production Fundamentals and Technology Advances. CRC Press. New York, USA.

[2] Nikolaidis, P., \& Poullikkas, A. (2017). A comparative overview of hydrogen production processes. Renewable and Sustainable Energy Reviews, 67: 597-611.

[3] Rahman, S. N. A., Masdar, M. S., Rosli, M. I., Majlan, E. H., Husaini, T., Kamarudin, S. K., \& Daud, W. R. W. (2016). Overview biohydrogen technologies and application in fuel cell technology. Renewable and Sustainable Energy Reviews, 66: 137-162.

[4] Sun, Y., He, J., Yang, G., Sun, G. and Sage, V.(2019). A review of the enhancement of biohydrogen generation by chemicals addition. Catalysts, 9 (353): 2-21

[5] Rathore, D., Singh, A., Dahiya, D. and Nigam, P.S. (2019). Sustainability of biohydrogen as fuel: Present scenario and future perspective. AIMS Energy 7(1): 1-19. 
[6] Eroglu, E., \& Melis, A. (2011). Bioresource Technology Photobiological hydrogen production: Recent advances and state of the art, Photobiological hydrogen production: Recent advances and state of the art. Bioresource Technology, 102: 8403-8413

[7] Nagarajan, D., Lee, D. J., Kondo, A., \& Chang, J. S. (2017). Recent insights into biohydrogen production by microalgae - From biophotolysis to dark fermentation. Bioresource Technology, 227(1): 373-387.

[8] Assawamongkholsiri, T.and Reungsang, .A.(2015). Photofermentational hydrogen production of rhodobacter sp. KKU-PSI isolated from an USAB reactor. Electronic Journal of Biotechnology 18: 221-230.

[9] Sharma, A. and Arya, S.K.(2017). Hydrogen from algal biomass: A review of production process. Biotechnology Reports 15: 63-69.

[10] Cardoso, V., Romao, B.B., Silva, F.T.M., Santos, J.G., Batista, F.R.X. and Ferreira, J.S.(2014). Hydrogen production by dark fermentation. Chemical Engineering Transactions 38: 481-486.

[11] Rameirez-Morales, J.E., Tapia-Venegas, E., Toledo-Alarcon, J, and Ruiz-Filippi, G.(2015). Simultaneous production and separation of biohydrogen in mixed culture systems by continous dark fermentation. Water Science and Technology 71(9): 1271-1285

[12] Schröder, C., Selig, M., \& Schönheit, P. (1994). Glucose fermentation to acetate, $\mathrm{CO}_{2}$ and $\mathrm{H} 2$ in the anaerobic hyperthermophilic eubacterium Thermotoga maritima: involvement of the Embden-Meyerhof pathway. Archives of Microbiology, 161(6): 460-470.

[13] Kraemer, J.T and Bagley, D.M (2008). Measurement of H2 consumption and its role in continuous fermentative hydrogen production. Water Science Technology 57 (5): 681-685.

[14] Hema, R. and Agrawal, P.(2012). Production of clean feul from waste biomass using combined dark and photofermentaion. IOSR Journal of Computer Engineering 1(4), 37-47.

[15] Wang, J. and Yin, Y.(2018). Fermentative hydrogen production using pretreated microalgal biomass as feedstock. Microbial Cell Factories $17: 22$

[16] Fatima,S., Kumar, A.and Singh, R.K.(2018). Biohydrogen prodyuction: A potential energy resource. International Journal of Engineering Science and Advanced Research 4(3), 1-10.

[17] Bakonyi, P., Nemestothy, N. and Belafi-Baka, K.(2013). Biohydrogen purification by membranes: An overview on the operational conditions affecting the performance of non-porous, polymeric and ionic liquid based gas separation membranes. International Journal of Hydrogen Energy, 38(23), 9673-9687.

[18] Morsy, F. M. (2015). $\mathrm{CO}_{2}$ free biohydrogen production by mixed dark and photofermentation bacteria from sorghum starch using a modified simple purification and collection system. Energy, 87, 594-604.

[19] Volkl, J., Muller, K., Mokrushina, L., and Arlt, W.(2012). A priori property estimation of physical and reactive $\mathrm{CO}_{2}$ absorbents. Chem. Eng. Technol. 35(3), 579-583.

[20] Radebaugh, R. (2007). Historical Summary of Cryogenic Activity Prior to 1950. In K. D. Timmerhaus \& R. P. Reed (Eds.), Cryogenic Engineering (pp. 3-27). New York, NY: Springer New York

[21] Xu, G., Liang, F., Yang, Y., Hu, Y., Zhang, K. and Liu, W.(2014). An improved $\mathrm{CO}_{2}$ separation and purification system based on cryogenic separation and distillation theory. Energies 7, 3484-3502.

[22] Lal, B., Shariff, A.M., Mukhtar, H., Nasir, Q. and Qasim, A.(2018). An overview of cryogenic separation techniques for natural gas with high $\mathrm{CO}_{2}$ content. Journal of Engineering and Applied Sciences 13(8), 2152-2155.

[23] Bharathiraja, B., Sudharsanaa, T., Bharghavi, A., Jayamuthunagai, J., \& Praveenkumar, R. (2016). Biohydrogen and Biogas - An overview on feedstocks and enhancement process. Fuel, 185, 810-828

[24] Gunardson, H. (1998). Industrial gases in petrochemical processing. Chemical industries. New York: Marcel Dekker

[25] Damle, A. (2008). Hydrogen Separation and Purification. In Hydrogen Fuel, 283-324. CRC Press.

[26] Keller, T., \& Shahani, G. (2016). PSA technology: Beyond hydrogen purification. Chemical Engineering, 123(1), 50-53.

[27] Grande, C.A.(2012). Advances in pressure swing adsorption for gas separation. International Scholarly Research Network ISRN Chemical Engineering, 2012 (9829341), 1-13

[28] Moon, D. K., Lee, D. G., \& Lee, C. H. (2016). H2 pressure swing adsorption for high pressure syngas from an integrated gasification combined cycle with a carbon capture process. Applied Energy, 183, 760-774.

[29] Li, B., He, G., Jiang, X., Dai, Y.and Ruan, X.(2016). Pressure swing adsorption/membrane hybrid processes for hydrogen purification with a high recovery. Frontiers of Chemical Science and Engineering. 10(2): 255-264. 
[30] Zakkour, P., \& Cook, G. (2010). CCS Roadmap for Industry: High-purity $\mathrm{CO}_{2}$ Sources: Final Draft Sectoral Assessment, (September), Report to the United Nations Industrial Development Organisation (UNIDO)

[31] Li, T., \& Keener, T. C. (2016). A review: Desorption of $\mathrm{CO}_{2}$ from rich solutions in chemical absorption processes. International Journal of Greenhouse Gas Control, 51, 290-304.

[32] Abdul M.N.A. and Asli U.A (2019) Purification of biohydrogen from fermentation gas mixture using two-stage chemical absorption. In: E3S Web of Conferences 90. 01012

[33] Optimized Gas Treating. (2008). Piperazine - Why It's Used and How It Works. The Contactor - Optimized Gas Treating, Inc, 2(4), 2. Retrieved from http://www.ogtrt.com/files/contactors/vol_2_issue_4.pdf Access on 27/11/2019

[34] Chung, Y.T., Rohani, R., Mohamad, I.N, Mastar@Masda, M.S and Takriff, M.S.(2019). Purification of biohydrogen produced from palm oil mill effluent fermentation for fuel cell application. Malaysian Journal of Analytical Sciences, 80-89.

[35] Li, P., Wang, Z., Qiao, Z., Liu, Y., Cao, X., Li, W., and Wang, S. (2015). Recent developments in membranes for efficient hydrogen purification. Journal of Membrane Science, 495, 130-168.

[36] Yin, H. and Yip, A.C.K. (2017). A review on the production and purification of biomas-derived hydrogen using emerging membrane technologies. Catalysis 7, 297.

[37] Kohl, A. L., \& Nielsen, R. B. (1997). Chapter 15 - Membrane Permeation Processes. In Gas Purification, 1238-1295.

[38] Yin, H., \& Yip, A. C. K. (2017). A Review on the Production and Purification of Biomass-Derived Hydrogen Using Emerging Membrane Technologies. Catalysts, 7(10), 297.

[39] Sazali, N., Mohamed, M.A., and Salleh, W.N.W.(2020). Membranes for hydrogen separation: a significant review. The International Journal of Advanced Manufacturing Technology 107, 1859-1881.

[40] Bakonyi, P., Nemestothy, N. and Belafi-Baka, K.(2013). Biohydrogen purification by membranes: An overview on the operational conditions affecting the performance of non-porous, polymeric and ionic liquid based gas separation membranes. International Journal of Hydrogen Energy.

[41] Bakonyi,P., Nemestothy, N., Lanko, J., Rivera, I., Bultron, G. and Belafi-Baka, K. (2015).Simultaneous biohydrogen production and purification in adouble-membrane bioreactor system. International Journal of Hydrogen Energy 40, 1690-1697

[42] Antonini, T., Foscolo, P.U., Gallucci, K.and Stendardo, S.(2015). Influence of temperature on oxygen permeation through ion transport membrane to feed a biomass gasifier. Journal of Physics: Conference Series 655, 012034.

[43] Lasseuguette, E., Malpass-Evans, R., Carta, M., McKeown, N.B. and Ferrari, M.(2018). Temperature and pressure dependence of gas permeation in a microporous Troger's base polymer membranes(Basal) 8(4):132.

[44] Malagon-Romero, D.H., Ladino, A., Ortiz, N. and Green, L.P.(2016). Characterization of a polymeric membrane for the separation of hyd rogen in a mixtutre with $\mathrm{CO}_{2}$. The Open Fuels and Energy Science Journal 9, 126-136.

[45] Smit, B., A.Reimer, J., Oldenburg, C. M., \& Bourg, I. C. (2014). Introduction to Carbon Capture and Sequestration. Imperial College Press 